\title{
Pengembangan Alat Ukur Hurdle Jump untuk Daya Tahan Otot Tungkai Berbasis Sensor Ultrasonik
}

\author{
Qiefrydzannath ${ }^{\bowtie}$, Agus Rusdiana \\ Program Studi Ilmu Keolahragaan \\ Fakultas Pendidikan Olahraga Kesehatan \\ Universitas Pendidikan Indonesia \\ Jln. Dr. Setiabudhi no 229, Kota Bandung
}

\section{Kata Kunci:}

Daya tahan, hurdle jump, mikrokontroller, otot tungkai, research \& development,.sensor ultrasonic.

\begin{abstract}
Penelitian ini bertujuan mengembangkan alat ukur hurdle jump untuk daya tahan otot tungkai berbasis sensor ultrasonik. 10 orang mahasiswa program studi Ilmu Keolahragaan berpartisipasi sebagai sampel dalam penelitian kali ini. Penelitian ini menggunakan pendekatan metode Research and Development (R\&D). Alat yang digunakan menggunakan rangkaian elektronika berbasis sensor ultrasonik dan mikrokontroller. Alat ini bekerja otomatis dengan menekan tombol start pada box ditandai dengan suara buzzer sebanyak 3 kali sebagai tanda test akan dimulai. Ketika sampel melakukan lateral jump selama 60 detik maka alat ini secara ototmatis akan menghitung gerakan hurdle jump ditandai dengan suara buzzer ketika masuk dalam point dan buzzer akan berbunyi ketika durasi waktu sudah habis. Hasil tampilan waktu dan hasil gerakan hurdle jump akan tertera pada LCD yang terletk pada permukaan box.
\end{abstract}

\begin{abstract}
This research aims to develop a hurdle jump measurement tool for the endurance of limb muscles based on ultrasonic sensors. 10 students of the Sports Science study program participated as a sample in this study. This study uses a Research and Development (R\&D) method approach. The instrument used uses an electronic circuit based on ultrasonic sensors and a microcontroller. This tool works automatically by pressing the start button on the box marked with a buzzer sound 3 times as a sign the test will start. When the sample performs a lateral jump for 60 seconds, this tool will automatically calculate the hurdle jump movement marked by the buzzer sound when entering the point and the buzzer will sound when the time duration is up. The results of the time display and the results of the hurdle jump movement will be displayed on the LCD located on the surface of the box.
\end{abstract}

(C) 2019 Universitas Pendidikan Indonesia

\footnotetext{
Alamat korespondensi:

Prodi Ilmu Keolahragaan

Jln. Dr. Setiabudhi no 229, Kota Bandung

E-mail: rqiefrydzannath@gmail.com
} 


\section{PENDAHULUAN}

Pada abad modern ini kemajuan teknologi dalam semua bidang cabang ilmu sudah menjadi bagian yang tidak terpisahkan. Inovasi dalam guna menunjang peningkatan pencapaian prestasi.

Permasalahan yang terjadi dalam pengukuran daya tahan otot tungkai seperti squat jump atau dengan lateral hurdle jump saat ini masih menghitung manual dan menghitung waktu dengan mengunakan stopwatch. Menghitung manual pun menjadi masalah karena tingkat konsentrasi yang dimiliki setiap orang berbeda serta Pengunaan Stopwatch menjadi masalah dalam keakuratan data yang dimabil karena adanya perbedaan selang waktu dalam penekanan tombol. Sehingga dapat banyak menimbulkan kesalahan (Human error) karena tingkat repleks dan kepekaan manusia berbeda-beda.

Dengan adanya permasalah tersebut maka peneliti berinovasi untuk melakukan pengembangan alat ukur hurdle jump berbasis sensor ulltrasonik. Inovasi yang akan dilakukan diantaranya, pertama membuat alat ini menggunakan 2 (dua) sensor ultrasonik yang terletak pada kedua sisi tiang hurdle jump sehingga point akan terhitung apabila objek berpindah seutuhnya ketika melakukan lateral jump dari tempat satu ke tempat lainnya yang sudah ditentukan, sehingga apabila ada tambahan gerakan tidak akan terpengaruh masuk dalam point box LCD. Kedua, kerangka hurdle jump terbuat dari besi berat dan halang rintang yang digunakan berupa karet elastis agar tingkat safety bisa terjaga.

Alat ini diharapkan supaya meminimalisir tingkat human error yang terjadi apabila saat melakukan test hurdle jump.. Dalam penelitian ini, peneliti akan bekerjasama dengan mahasiswa yang ahli dalam bidang teknik elektro untuk menciptakan Teknologi alat hurdle jump berbasis sensor ultrasonik.

\section{METODE}

Metode yang digunakan adalah metode $\mathrm{R}$ \& D karena hasil akhir penelitian ini akan menghasilkan produk alat hurdle jump berbasis sensor ultrasonik.. Peneliti menetapkan partisipan sebagai berikut karena pada pengujian kali ini hanya digunakan untuk melihat kinerja alat. Sampel pada penelitian ini adalah melibatkan 10 mahasiswa ilmu keolahragaan sebagai sampel penelitian karena terbiasa melakukan aktivitas olahraga serta memiliki tingkat kebugaran yang baik.

Validasi yang tepat yaitu dengan menggunakan ahli olahraga dan elektro, hasil uji validitas ini merupakan hasil dari penilaian ahli tersebut terkait desain alat, akurasi sensor ultrasonik, konsistensi sensor ultrasonik dan efektifitas tiap Komponen.

menganalisis hasil data dengan statistical product and service solutions (SPSS) untuk menguji normalitas, homogenitas, dan uji komparasi. Sesuai dengan tujuan uji coba yaitu untuk mengetahui apakah terdapat perbedaan antara hurdle jump manual dengan hurdle jump menggunakan sensor dengan independent sample t-test. Syarat untuk uji t yaitu data harus normal dan homogen. Uji normalitas menggunakan one sample kolmogorov smirnov. 10 langkah dikembangkan oleh Sugiyono, hanya 6 langkah yang akan diadaptasikan pada penelitian kali ini yaitu langkah 1 sampai dengan 6 , berikut adalah alur penelitian yang digunakan pada penelitian ini :
1. Potensi dan Masalah
2. Pengumpulan Informasi
3. Desain Produk
4. Validasi Desain
5. Perbaikan Desain
6. Uji Coba Produk

pertama, potensi dan masalah. Pengembangan teknologi alat hurdle jump berbasis sensor ultrasonik menjadi sebuah potensi untuk dilakukan penelitian dan pengembangan karena terdapat potensi masalah yang ada saat ini, alat ukur bantu untuk menghitung lateral jump pada alat hurdle jump tergolong manual sehingga akan timbul kesalahan dalam proses penghitungan yang berpeluang akan terjadinya human error, dikarenakan tingkat konsentrasi setiap orang 
berbeda-beda. Adanya alat ukur hurdle jump berbasis sensor ultrasonik dapat menyelesaikan masalah terjadinya human error yang ditimbulkan oleh alat manual. Oleh karena itu adanya pengembangan alat ukur ini diharapkan dapat membantu perkembangan prestasi olahraga di Indonesia.

Kedua, Proses pengumpulan informasi dilakukan secara faktual dengan konsultasi kepada beberapa orang yang mempunyai kemampuan di bidang biomekanika olahraga agar dapat mengatasi masalah dalam proses test. peneliti pun mengumpulkan berbagai informasi dari artikel, situs-situs, sumber buku karya ilmiah, journal, e-book, buku-buku referensi kuliah yang berhubungan dengan program yang akan dikembangkan. Peneliti juga melakukan konsultasi dengan mahasiswa teknik elektro UPI tentang pembuatan alat ini untuk melakukan kerjasama dalam membuat produk yang akan dikembangkan.

Ketiga, Desain produk atau model yang dihasilkan adalah terciptanya alat ukur hurdle jump untuk daya tahan otot tungkai berbasis sensor ultrasonik yang dapat menghitung jumlah gerakan lateral jump serta menghasilkan data tampilan pada box LCD.

Keempat, Validasi desain merupakan proses kegiatan untuk menilai apakah rancangan produk lebih efektif atau tidak, produk dalam hal ini, adalah alat hurdle jump berbasis sensor ultrasonik. Setelah terbuatnya desain produk maka perlu divalidasi untuk penilaian agar diketahui kekurangan dan kelebihan dari produk tersebut. Sugiyono (2012, hlm. 302) mengungkapkan bahwa "validasi desain merupakan proses kegiatan untuk menilai apakah rancangan produk, dalam hal ini sistem kerja rasional akan lebih efektif dari yang lama atau tidak". Pada proses validasi melibatkan pernyataan dari para ahli/pakar. Tingkat validitas alat ini yaitu menguji alat hurdle jump berbasis sensor ultrasonik dengan cara user melakukan gerakan lateral jump untuk mengetahui konsistensi yang dihasilkan oleh sensor ultrasonik yang kemudian hasil gerakannya ditampilkan pada box LCD.
Langkah selanjutnya setelah melakukan validasi yaitu perbaikan. Pada proses perbaikan peneliti melakukan diskusi dengan pakar dan ahli dalam bidang teknologi olahraga dan bidang teknik elektro dilakukan untuk menilai kualitas rancangan alat ini.

Kelima, Setelah desain produk berupa rancangan alat di evaluasi dan dianalisis oleh para pakar maka akan menghasilkan berbagai masukan dan kelemahan dari rancangan tersebut. Dari hasil inilah kemudian akan dilakukan beberapa perubahan yang menjadikan alat ini menjadi berkualitas. Jika tidak terdapat revisi maka peneliti melanjutkan ke langkah penelitian yang selanjutnya.

Keenam, Setelah perbaikan desain maka dilakukan uji coba produk. Uji coba produk bisa dilakukan beberapa kali sesuai dengan kebutuhan analisis. Untuk pengujian tersebut dilakukan dengan membandingkan efektivitas dan efisiensi sistem kerja alat yang lama dengan yang baru. Alat pengukuran ini dikatakan berhasil apabila dalam proses penghitungan yang dihasilkan tepat dan deteksi dari sensor ultrasonik tersebut sesuai dengan data yang dikeluarkan dari box LCD.

Alat ini akan bekerja secara otomatis Ketika adaptor universal terhubung ke sumber listrik dan box LCD akan menyala dan terdapat tampilan jump count dan waktu hitungan mundur selama 60 detik. Ketika test akan dimulai maka tekan tombol start dan buzzer akan bunyi sebanyak 3 kali sebagai tanda test akan segera dimulai, ketika user melakukan lateral jump ke kanan dan ke kiri maka secara otomatis sensor ultrasonik menangkap hasil gerakan ditandai dengan suara buzzer dan apabila test akan berakhir makan buzzer dengan irama panjang akan berbunyi kembali sebagai tanda test berakhir. Apabila ingin memulai kembali maka tekan tombol reset. 


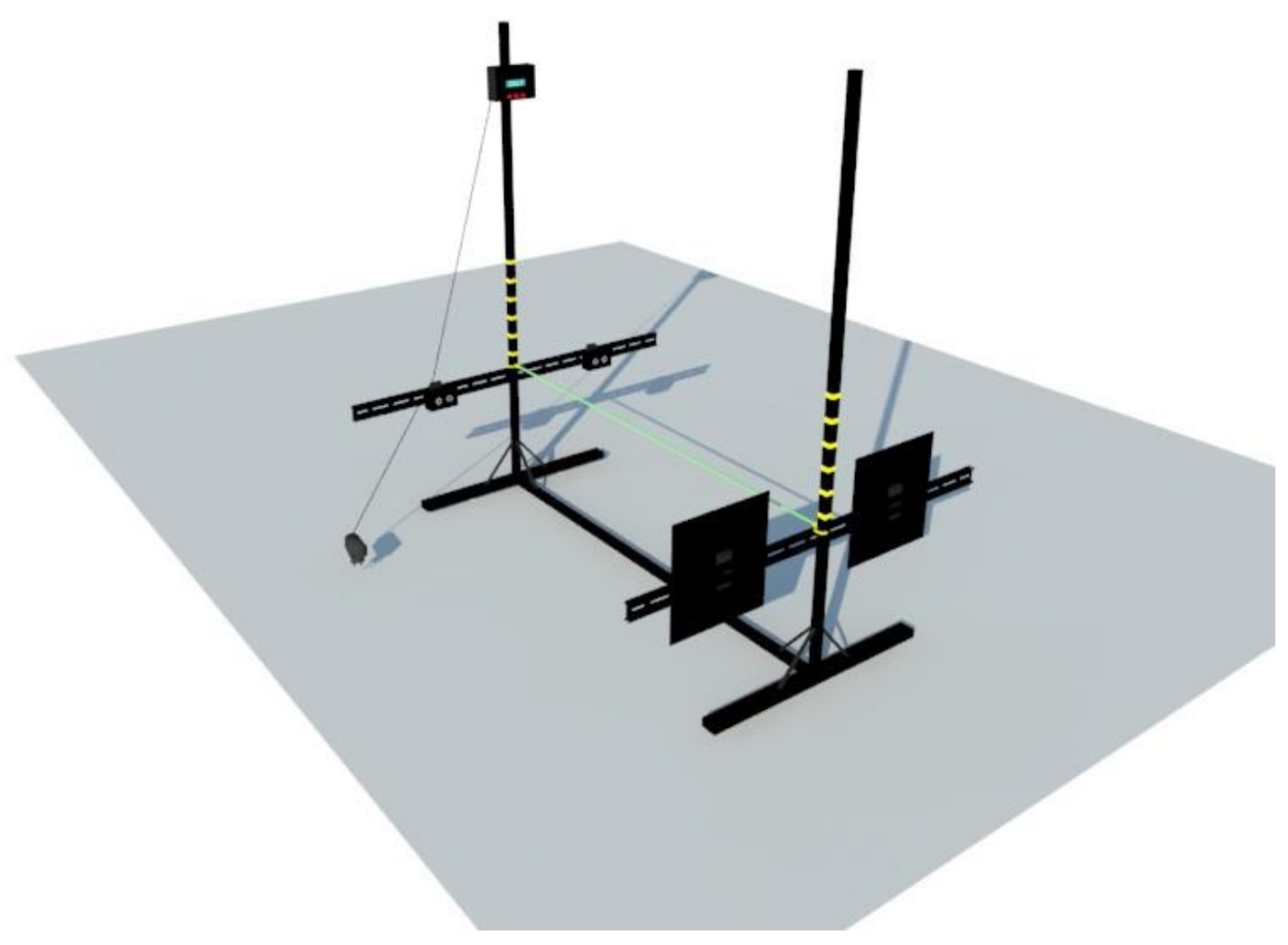

Gambar 1. Desain Keseluruhan Alat Hurdle Jump

\section{HASIL DAN PEMBAHASAN}

\section{a. Sistem Kerja}

Alat ini akan bekerja secara otomatis Ketika adaptor universal terhubung ke sumber listrik dan box LCD akan menyala dan terdapat tampilan jump count dan waktu hitungan mundur selama 60 detik. Ketika test akan dimulai maka tekan tombol start dan buzzer akan bunyi sebanyak 3 kali sebagai tanda test akan segera dimulai, ketika user melakukan lateral jump ke kanan dan ke kiri maka secara otomatis sensor ultrasonik menangkap hasil gerakan ditandai dengan suara buzzer dan apabila test akan berakhir makan buzzer dengan irama panjang akan berbunyi kembali sebagai tanda test berakhir. Apabila ingin memulai kembali maka tekan tombol reset.

\section{b. Uji Coba Produk}

Uji coba produk alat hurdle jump berbasis sensor ultrasonik dilaksanakan di Sport Science Laboratory FPOK UPI dengan melibatkan 10 mahasiswa ilmu keolahragaan. Langkah selanjutnya menganalisis data dengan statistical product and service solutions (SPSS) untuk menguji normalitas, homogenitas, dan uji komparasi. Sesuai dengan tujuan uji coba yaitu untuk mengetahui apakah terdapat perbedaan antara hurdle jump manual dengan hurdle jump menggunakan sensor dengan independent sample t-test. Syarat untuk uji t yaitu data harus normal dan homogen. Uji normalitas menggunakan one sample kolmogorov smirnov. Hasil Analisis Uji Normalitas .apabila nilai $p>$ 0,05 maka data normal dan data tidak normal apabila $\mathrm{p}<0,05$. Nilai signifikansi dari test alat hurdle jump yaitu 0,999 maka data tersebut normal. Dan nilai signifikansi dari test manual 
hurdle jump yaitu 0,994 maka data tersebut normal.

Hasil Analisis Uji Homogenitas menggunakan uji levene yaitu Nilai signifikansi (p) harus lebih besar dari 0,05 untuk membuktikan bahwa data berdistribusi homogen. Nilai signifikansi dari test alat dan manual yaitu 0,722 maka data berdistribusi homogeny.

Hasil Analisis Uji Komparasi menggunakan independent sampel $t$ test yaitu nilai akurasi patokan untuk nilai signifikansinya dapat dirubah menjadi $99 \%$. Jika nilai akurasi patokan 0,05 adalah $95 \%$, maka $99 \%$ adalah 0,01 . Jadi, bila nilai signifikansi berada dibawah 0,01 , maka barulah hasil data tersebut memiliki perbedaan. dan jika nilai signifikansi lebih besar dari 0,05, maka tidak terdapat perbedaan.

$\mathrm{HO}$ : tidak terdapat perbedaan yang signifikan antara hasil tes manual dengan tes menggunakan alat
H1 : Terdapat perbedaan yang signifikan antara hasil tes manual dengan tes menggunakan alat.

Nilai signifikansi dari test alat dan test manual yaitu $\mathrm{p}=0,770>0,01$, maka H0 Diterima

Kesimpulan dari uji coba yaitu Analisis uji-t menggunakan asumsi bahwa varian sama yakni berpatokan pada equal variances assumed. Dinyatakan $\mathrm{p}=0,722>0,05$; maka H0 diterima. Jadi tidak terdapat perbedaan antara tes manual dengan tes menggunakan alat yaitu memiliki hasil rata-rata yang tidak begitu jauh berbeda, yaitu hasil alat manual memiliki nilai 52,3 dan menggunakan alat bersensor 50,8 namun dari hasil tersebut nilai rata-rata menggunkan alat bersensor sedikit lebih rendah dikarnakan apabila user saat melakukan lateral jump tidak tepat jatuh di depan sensor ultrasonik maka tidak akan masuk point pada box LCD.

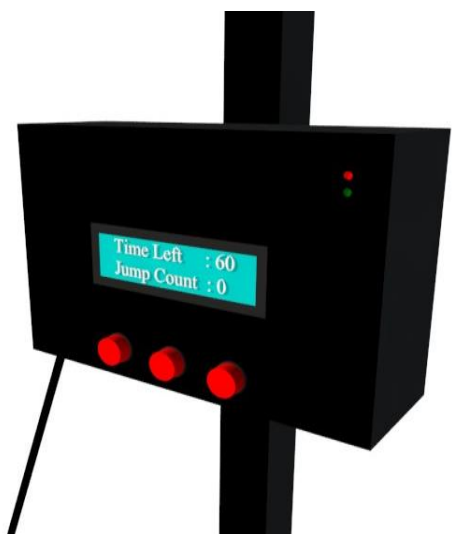

Gambar 2. Box LCD Hurdle Jump

Alat hurdle jump berbasis sensor ultrasonik telah diprogram sesuai kebutuhan untuk tes daya tahan otot tungkai guna memnimalisir terjadinya human error. Pada penelitian ini peneliti melakukan inovasi pengembangan pada alat sebelumnya diantaranya pertama membuat alat ini menggunakan 2 (dua) sensor ultrasonik yang terletak pada kedua sisi tiang hurdle jump sehingga point akan terhitung apabila objek berpindah seutuhnya ketika melakukan lateral jump dari tempat satu ke tempat lainnya yang sudah ditentukan, sehingga apabila ada tambahan gerakan tidak akan terpengaruh masuk dalam point box LCD. Kedua, kerangka hurdle jump terbuat dari besi berat dan halang rintang yang digunakan berupa karet elastis agar tingkat safety bisa terjaga.

\section{KESIMPULAN}

Alat ukur hurdle jump untuk daya tahan otot tungkai berbasis sensor ultrasonik berhasil dirancang dan dikembangkan. Alat ini telah dikembangkan oleh penulis dengan pengembangan berupa penghitungan waktu dan 
jumlah gerakan tes hurdle jump yang dihitung menggunakan sensor yang terdapat pada alat tersebut.

Komponen utama pada alat ukur hurdle jump berbasis sensor ultrasonik ini yaitu terdapat dua sensor ultrasonik, arduino nano, mikrokontroller ATMEGA 32, box LCD, buzzer dan adaptor universal. Pada alat ini dua pasang sensor ultrasonik lah yang berperan menghitung gerakan lateral jump yang dipasang pada tiang hurdle. Untuk membuat alat ini diperlukan waktu selama satu bulan, dengan bantuan dari ahli elektronika dan mekanika.

Sistem kerja pada alat ini intinya yaitu sebagai pendeteksi penghitung otomatis gerakan lateral jump dengan menggunakan sensor dan data akan diolah kedalam mikrokontroller, dan angka hasil penghitungan gerakan akan muncul pada box LCD. Buzzer akan berbunyi sebagai penanda start, masuknya point gerakan dan durasi waktu sudah habis.

Validator ahli mengatakan bahwa desain alat, akurasi sensor ultrasonik, konsistensi sensor ultrasonik, fungsi tiap Komponen dan efektifitas tiap Komponen berjalan sangat baik.

Setelah dilakukan uji statistik menggunakan SPSS uji komparasi independent sample $t$ test hipotesis statistik yang diterima yaitu tidak terdapat perbedaan tes manual dan tes menggunakan alat bantu berupa sensor, buzzer serta microcontroller yang telah dibuat dengan perhitungan selama 60 detik untuk tes daya tahan otot tungkai.

Rekomendasi yang dapat peneliti sarankan yaitu pertama perlu adanya Perlu adanya dukungan dari semua pihak khususnya program studi Ilmu Keolahragaan untuk melanjutkan penelitian dan pengembangan alat ini agar lebih baik.s.

\section{DAFTAR PUSTAKA}

Bompa. (1994). Power Training for Sport, Plyometric for Maximum Power Development. Canada : Coaching Association of Canada.
Cayoto. (2007). Pengaruh Latihan Knee Tuck Jump dan Barrier Hop Terhadap Hasil Tendangan Bola Lambung Jauh. Semarang: Universitas Negeri Semarang.

Depdiknas. (2000) Pedoman dan Modul Pelatihan Kesehatan Olahraga Bagi Pelatihan Olahragawan Pelajar. Jakarta : Depdiknas

Donald A. Chu. (1992) Jumping Into Plyometrics. Champaign, IIinois:

Human Kinetics Pub.

Dwi, Singgih P. (2016). Pengembangan Alat Ukur Hurdle Jump Untuk Daya Tahan Otot Tungkai Berbasis Ultrasonik. Skripsi. Bandung: FPOK UPI.

Hoffman, Jay. (2006) Norms for fitness, performance, and health. USA :

Human Kinetics.

Iman, Imanudin (2008). Ilmu Kepelatihan : Bandung

Iman, Imanudin (2014). Ilmu Kepelatihan : Bandung

Putra, Domi (2013). Pengaruh Latihan Box Jump dan Barrier Hop Terhadap Kekuatan Otot Tungkai. Jambi : Universitas Jambi.

Radcliffe, J. C \& Farentinos, R.C. (1985) Plyometrics Explosive Power Training. 2ND ed. Champaign , Illionis: Human Kinetics Published, Inc.

Sugiyono. (2010). Metode Penelitian Kuantitatif, Kualitatif, dan R \& D. Bandung : Alfabeta.

Sugiyono. (2011). Metode Penelitian Kuantitatif, Kualitatif, dan R \& D. Bandung : Alfabeta.

Sugiyono. (2012). Metode Penelitian Kuantitatif, Kualitatif, dan R \& D. Bandung : Alfabeta.

Sugiyono. (2014). Metode Penelitian Pendidikan Kuantitatif, Kualitatif, dan R \& D. Bandung : Alfabeta.

Wahjoedi. (2000). Landasan Evaluasi Pendidikan Jasmani. Jakarta : PT. Raja Grafindo. 